\title{
Research on the Basic Course Teaching of Visual Communication Design Based on Innovation Ability Training
}

\author{
Bailin Xiao \\ Northeast Electric Power University \\ Jilin, China
}

\begin{abstract}
As the staring point for the students of visual communication design to enter the design field, the basic design course is the connecting point of transformation from basic drawing education to basic design education. It is also an important process for students to establish the systematic concept of visual communication design. It is more important for basic design course to train students' innovation ability in design. At present, the basic course teaching of visual communication design is limited. It is necessary to strengthen the teaching idea of innovation ability training, build scientific basic course system of design and optimize the contents of basic design course as well as implement four measures to diversify the methods of course assessment, in order to train students' innovation ability.
\end{abstract}

Keywords-innovation ability training; basic design course; teaching research

\section{INTRODUCTION}

As an important part of three core fields in the art and design, the specialty of visual communication design contains contents of the traditional plane design and expands continuously with the scientific progress, the development of new media technology and the application of new energy and material. Furthermore, it forms a new design field with close relation and collaboration with other visual media through combination with other fields. It is the important content for the visual communication design specialty to train high quality design talents with creative thinking and innovation ability.

Currently, the course of visual communication design specialty in colleges consists of basic design course and professional course which are progressive under the system of visual communication design specialty. As the origin for students of the visual communication design specialty to enter the design field, the basic design course is the connecting point of transformation from basic drawing education to basic design education. It is also an important process for students to establish systematic concept of visual communication design. Students should learn design skills and accumulate design experience in basic design course. More importantly, it gradually trains students' innovation ability in design.

\section{LiMITATION OF BASIC COURSE TEACHING OF VISUAL COMMUNICATION DESIGN}

Design basis is the basic platform to establish visual communication design. The course includes basic disciplinary knowledge of this specialty (the basic design course in this paper not only include the modeling basis and the constitution basis in traditional concept) like typeface, format, figure, printing and design history. These courses are independent and connective. The basic course of visual communication design mainly covers the design basis of expression, technology and theory. With the continuous development of times, technology and design concept, the education of visual communication design also adjusts.

\section{A. Limitation in Understanding the Course Nature}

The teaching of visual communication design integrates the training of students' innovation ability in teaching professional course and fails to train innovation ability in teaching basic design course. The basic teaching of visual communication design emphasizes model expression ability and the ability to skillfully use visual expression skills. However, the overemphasis of skills and the neglect of training creative thinking and innovation ability will make students form thinking set. Many professional teachers also think the basic design course aims at letting students grasp design theory and basic skills and the training of innovation ability is the task in professional course. The limitation in cognition mixes the relationship between basis and innovation. Therefore, the basic design course is provided to grasp skills. Students' creative thinking is confined, let alone the innovation ability.

The visual communication design is a discipline of practical application. Researches on teaching of basic design course pay more attention to training students' practical ability. It emphasizes the practice instead of the theory. Teachers neglect the basic courses of design theory like History of Design, Design Culture Research, Design Principle and Design Methodology in teaching, and repeat what the book says. Students memorize mechanically according to the notes. The learning of design theory becomes low level learning of knowledge, failing to support the professional practice. The theory separates from the practice. It is wrong to divide the basic course teaching of visual communication design into the 
theoretical and the practical. Instead, the theory and the practice is an interactive unity. Practice is the essential property of design. But design will be castle in the air without the guidance of theory on practice. The learning of basic design theory is important for students to learn the professional knowledge and the integration of innovation ability training.

\section{B. The Course Content Is Single and Stylized}

It is a substantive problem that the contents of basic course in visual communication design are single and the teaching process is stylized. The name of visual communication design specialty was determined in 2012. It was called plane design before this time. Nowadays, the course of visual communication design specialty follows the previous course system of plane design. The basic design courses provided include professional modeling (sketch and color), constitution design, decoration basis, graphic design, character design, format design, package modeling design, computer aided design and design theory, which are traditional courses. Although the names of some courses are modified, teachers often continue the teaching procedure existing for many years. It fails to conform to the development of specialty and arouse students' interest in learning and exploration. Students spend most energy in completing assignments related to skill training, so that they have few time to think deeply or innovate in the task design, leading to imitative practice design. For example, in plane composition, teachers will teach theories like the concept and the principle of composition according to requirements of teaching syllabus and then give assignments of design training. Students complete the assignment according to the example for teachers to guide and comment. In this process, students only design formally and seldom consider the design creativity and thinking analysis. The insufficient understanding of basic design course directly makes the course contents follow the traditional contents and neglect the importance of theory basis and humanistic knowledge in ability training.

\section{The Pattern of Course Setting Is Fixed.}

The setting of basic course in visual communication design lacks long-term reasonable plan for the training objective of innovative design talents. Generally speaking, it follows the pattern of theory prior to practice, modeling prior to composition, drawing prior to figure, realistic painting prior to transformation, concrete prior to abstract, plane prior to threedimension and technology prior to creativity. The sequence doesn't base on the internal logic rule of courses but accumulate the experience on the basis of Bauhaus design education system. The fixed course setting neglects the systematic professional learning. The courses are independent and lack the connection and application of knowledge points. It is difficult for students to understand the teaching objectives of basic design course. It is adverse to train students' innovation ability.

\section{Separate from the Subsequent Professional Courses}

The separation of basic course teaching of visual communication from the subsequent professional courses mainly shows the basic design course and the professional course are independent closed system and lack internal connection. The teaching of design basis provides supports of theoretical cognition, expression technique, thinking analysis and ability training for the subsequent professional course. However, students fail to integrate the basic design knowledge in professional design in learning professional course. On one hand, it shows the system of basic design course is isolated and narrow in the whole education system; on the other hand, the teaching and training of skills and experience in basic design course cannot strongly support the professional teaching.

\section{IMPORTANCE TO TRAIN INNOVATION ABILITY IN BASIC DESIGN COURSE}

Basic design course is the important carrier of innovation ability training. In educational practice of design, we should realize the creative thinking and innovation ability of art is the continuous accumulation and reinforcement of knowledge and skill, intellectual ability and individual quality. Therefore, in basic design teaching, it is necessary to train students' innovation consciousness in accumulating knowledge and skill, and let them know that is innovation through teaching contents and means. The instrumental function of basic design course is irreplaceable. At the meantime, it shall also train students ability of logical thinking, scientific cognition, design management, humanistic quality and communication, which are important parts of innovation ability.

The period of basic design course is the best stage to train innovation ability. The training of innovation ability should not be periodical but run through the whole design education including the basic design course. Innovation cannot depend on a section or period of design. The period of basic design course is the best stage to train creative thinking and innovation ability. The period of professional course is to comprehensively apply and deepen the ability. The technology and the ability can be win-win if the teaching of basic design course can train creative thinking and ability.

\section{MEASURES To TRAIN INNOVATION ABILITY IN BASIC COURSE OF VisUAL COMMUNICATION DESIGN}

\section{A. Strengthen the Teaching Idea of Innovation Ability Training}

Innovation ability is not single skill or technology but a complicated and three-dimensional ability structure, namely the ability to solve problems creatively. It includes the creative thinking as well as cognition, emotion, will and skill. Knowledge is neither wisdom nor ability. The renowned physicist Laue says, it is more important to develop thinking ability than to acquire knowledge. Knowledge can become useful thing when we transform it into ability. The teaching of basic design course enables students to acquire knowledge and grasp expression skills. More importantly, it trains students' creative thinking and changes it into the ability to solve problems.

\section{B. Build Scientific System of Basic Design Course}

The scientific and reasonable course system of visual communication design can guarantee the teaching quality of this specialty, helping students to absorb professional 
knowledge and training their innovation ability. In the education of basic design course, reasonable setting of courses related to training of skills and creative thinking can effectively break students' fixed thinking modes and improve their ability of creative thinking. The training of students' innovation ability is systematic. It is far from enough to improve course setting. Innovative ideas should run through the basic design teaching to strengthen students' innovation consciousness. Different courses train students in different aspects. Therefore, it is better to coordinate the relationship between courses and arouse students' creative thinking and train their innovation ability. The teaching methods should be diversified. Teachers can apply different teaching means to bring more design inspiration fro students and then improve their innovation ability in design.

The visual communication design is comprehensive and complicated and integrates with other disciplines like social sciences, humanity, art and natural science, involving culture, society, history and economy. Therefore, in order to strengthen students' integrated quality and improve their innovation ability, the education of visual communication design must cooperate with other disciplines, break the single course system and expand students' professional knowledge, letting students find design inspiration in other discipline and form individualized creative concept.

\section{Optimize the Contents of Basic Design Course}

In order to train design talents with innovation ability, it is necessary to realize innovation is universal and exploitable. The universal innovation means innovation ability is an inborn ability of people. It evolves along with the evolution of human brain. The expression form is innovation potential. The exploitable innovation means the innovation ability of people can improve through stimulation, education and training. It transforms innovation potential into innovation ability. To stimulate and improve students' innovation ability in basic design course, firstly, teachers should make course contents close to professional practice and fully embody the open and diversified teaching contents to let students establish the thinking pattern combining rational thinking with emotional thinking. Secondly, change the thought to teach courses independently and integrate the dispersed and implicit knowledge structure to make it rich and systematic, logic and interesting, divergent and analytic, highlight the exploratory consciousness of task design. Lastly, when optimizing knowledge structure, teachers should train students' eyes, brain and hands. In addition, teachers can explore ways to train students' innovation ability, optimize the contents of basic course to strengthen their innovation consciousness, fully develop their creative potential in the basic stage of design education.

\section{Disconnect from the Subsequent Professional Courses}

The assessment methods of traditional basic design course include the theoretical closed-book exam and the overall evaluation of teachers. Both of them emphasize the learning results instead of the transformation of students' knowledge into ability including innovation ability. The result is accidental but the learning process of students is tangible.
Therefore, they have defects and fail to fully embody students' creative thinking and innovation ability. It is necessary to formulate diversified and operational assessment method from innovative thinking and skill expression according to characteristics of courses, to make it from the traditional "inspection assessment" to "learning-oriented assessment". For example, the course assessment should include self-assessment, group assessment and teacher assessment, to promote the learning, improvement and innovation. Teachers can also "use exhibition to replace the examination", letting students pay attention to learning process and seek difference, the new and change, training innovation ability and creating good learning atmosphere.

\section{CONCLUSION}

It is a systematic educational engineering to train the innovation ability of students in the visual communication design specialty. It is the best way to train students' innovation ability through the basic course of visual communication design. The research on basic course teaching of visual communication design is purposed to roundly improve the quality of basic teaching of visual communication design and achieve the teaching objective of training students' innovation ability.

\section{REFERENCES}

[1] Zheng Jianpeng. Analysis on Training of Applied Talents in the Specialty of Visual Communication Design [J], Design Art, 20139(2):23

[2] Gao Wei. Research on Basic Course Provision of Art and Design Major [D], Southwest University, 2009:53-55

[3] Fan Yinliang. Concrete and Abstract: New Thinking on Basic Course of Design Thinking [J], Decoration, 2014(11): 122-124 